\title{
IMPLEMENTASI MATEMATIKA PADA KEBUDAYAAN DI INDONESIA MELALUI INTERAKSI LINTAS BUDAYA MAHASISWA
}

\section{THE IMPLEMENTATION OF MATHEMATICS IN CULTURE IN INDONESIA THROUGH CROSS-CULTURAL INTERACTIONS}

\author{
Robia Astuti ${ }^{1{ }^{*}}$, Nurmitasari ${ }^{2)}$
}

${ }^{1)}$ FKIP, Universitas Muhammadiyah Pringsewu Lampung. email: robia.astuti@umpri.ac.id

${ }^{2)}$ FKIP, Universitas Muhammadiyah Pringsewu Lampung. email: nurmitasari@umpri.ac.id

\begin{abstract}
ABSTRAK
Tujuan kegiatan pengabdian ini adalah untuk memfasilitasi kegiatan interaksi lintas budaya melalui bingkai pertukaran mahasiswa Nusantara dengan mengungkap adanya implementasi matematika pada kebudayaan lokal yang ada di Indonesia. Kegiatan ini dilaksanakan pada tanggal 9 November 2020 melalui webinar nasional yang diikuti oleh mahasiswa yang tergabung dalam program PERMATA-SAKTI. Kemajuan teknologi informasi berbasis internet dan robotik yang biasa dikenal dengan nama revolusi industri 4.0 menjadi salah satu ancaman dan tantangan yang harus dihadapi agar keberadaan budaya tetap terjaga. Salah satu cara untuk melestarikan budaya tersebut adalah dengan memperkenalkan budaya pada mahasiswa melalui pembelajaran dengan cara mengintegrasikan budaya pada setiap mata kuliah. Oleh karena itu, melalui interaksi lintas budaya pada program PERMATA SAKTI ini sangat tepat untuk saling mengenalkan antar kebudayaan yang ada di Indonesia. Metode pelaksanaan kegiatan ini terdiri dari tiga tahapan yaitu tahap persiapan, tahap pelaksanaan dan tahap evaluasi. Kegiatan pada tahap persiapan yaitu mempelajari masalah tentang kebudayaan, mendata mahasiswa, dan melibatkan mahasiswa untuk bersama-sama menganalisis kebudayaan pada masing-masing daerahnya yang terintegrasi matematika. Kegiatan pada tahap pelaksanaan adalah membimbing mahasiswa memperkenalkan kebudayan daerahnya yang terintegrasi matematika, disajikan dalam bentuk video, dan dipresentasikan melalui webinar. Pada tahap evaluasi, mahasiswa merevisi video berdasarkan saran dosen dan peserta lain saat webinar.
\end{abstract}

Kata kunci: Interaksi Budaya, Matematika, Kebudayaan Indonesia, Webinar, Permata-Sakti

\section{ABSTRACT}

The purpose of this service activity is to facilitate cross-cultural interaction activities through the frame of Nusantara student exchange by revealing the implementation of mathematics in local cultures in Indonesia. This activity was carried out on November 9, 2020 through a national webinar which was attended by students who are members of the PERMATA-SAKTI program. The advancement of internet-based and robotic information technology which is commonly known as the industrial revolution 4.0 is one of the threats and challenges that must be faced so that the existence of culture is maintained. One way to preserve this culture is to introduce culture to students through learning by integrating culture in each subject. Therefore, through cross-cultural interactions in the PERMATA SAKTI program, it is very appropriate to introduce each other between cultures in Indonesia. The method of implementing this activity consists of three stages, namely the preparation stage, the implementation stage and the evaluation stage. Activities in the preparation stage are studying problems about culture, registering students, and involving students to jointly analyze the culture in their respective areas which are integrated with mathematics. The activity at the implementation stage is to guide students to introduce regional culture that is integrated with mathematics, presented in video form, and presented through webinars. In the evaluation stage, students revise the video based on suggestions from lecturers and other participants during the webinar.

Keywords: Cultural Interaction, Mathematics, Indonesian Cultures, Webinar, Permata-Sakti

Corresponding author: 
PENDAHULUAN

Sesuai UUD 45 pasal 32 bahwa kebudayaan sangat penting untuk memajukan bangsa Indoesia. Negara Indonesia merupakan Negara kepulauan yang mengakibatkan banyaknya suku bangsa dan menimbulkan banyaknya adat dan budaya. Namun kenyataannya warga Negara Indonesia tidak mengenal semua budaya yang ada di Negaranya. Contohnya ada suku Jawa yang tinggal di daerah Lampung tidak mengenal adat dan budaya Lampung. Adapun usaha pemerintah Indonesia yaitu dengan mengembangkan kurikulum pendidikan yang menuntut keterlibatan budaya dalam pembelajaran di sekolah dengan tujuan agar siswa dapat menjadi generasi yang berkarakter dan mampu menjaga serta melestarikan budaya sebagai landasan karakter bangsa [1]. Usaha tersebut direalisasikan dengan membelajarkan budaya pada matapelajaran muatan local di suatu satuan pendidikan pada tingkat dasar maupun menengah dan kegiatan PERMATA (Pertukaran Mahasiswa Tanah Air Nusantara) pada tingkat perguruan tinggi.

Belum juga mendapatkan hasil yang memuaskan dari usaha pemerintah Indonesia untuk memperkenalkan dan melestarikan keanegaragaman budaya di Indonesia hadirlah Revolusi Industri 4.0. Revolusi Industri 4.0 merupakan kemajuan teknologi informasi berbasis internet dan robotic. Sehingga dengan hadirnya revolusi industri 4.0 ini warga Negara Indonesia dapat mengakses lebih luas dan leluasa untuk mengetahui kebudayaan di Indonesia. Namun juga lebih leluasa dalam mengakses kebudayaan luar negeri. Oleh sebab itu revolusi industri 4.0 juga menjadi salah satu ancaman dan tantangan yang harus dihadapi agar keberadaan budaya tetap terjaga.

Ditambah pandemic Covid-19 yang melanda Negara Indonesia dari bulan Februari 2020 hingga sekarang belum mendapatkan solusi. Sehingga pembelajaran langsung berubah menjadi pembelajaran secara daring. Pembelajaran daring merupakan pembelajaran yang berada dalam jarngan/online, yang hanya tatap muka lewat virtual [2]. Kondisi ini membuat lebih berat tantangan dan ancaman yang harus dicarikan solusinya agar kebudayaan di Indonesia tidak ditinggalkan oleh warganya.

Salah satu warga Indonesia yang berperan dalam pembangunan dan dapat melestarikan serta menjaga kebudayaan Indonesia adalah Mahasiswa. Program pertukaran mahasiswa antar perguruan tinggi diseluruh Indonesia atau yang sekarang dikenal dengan istilah PERMATA-SAKTI (Pertukaran Mahasiswa Tanah Air Nusantara- Sistem Alih Kridit dengan Teknologi Informasi) dapat menjadi salah satu usaha bagi bangsa Indonesia dalam menjaga dan melestarikan kebudayaan Indonesia. Keanekaragamanan suku bangsa mahasiswa dapat memberikan pengetahuan antar mahasiswa tentang perbedaan budaya pada masing-masing suku bangsa. Dengan adanya kegiatan ini maka mahasiswa secara tidak langsung mau dan mampu mempelajari 
kebudayaan sendiri dan kebuadayaan orang lain.

Kebudayaan Indonesia tidak terlepas dari matematika. Matematika dan budaya adalah sesuatu yang tidak bisa dihindari dalam kehidupan sehari-hari, karena budaya merupakan kesatuan yang utuh dan menyeluruh, berlaku dalam suatu masyarakat sedangkan matematika merupakan pengetahuan yang digunakan manusia dalam menyelesaikan masalah sehari-hari [3]. Peran matematika pada aspek kebudayaan terlihat pada saat mendesain rumah adat, mengambar batik atau kain tradisional, menjumlah yang berkaitan dengan filosofi kebudayaan. Konsep matematika dapat digali dan ditemukan dalam budaya sehingga memperjelas bahwa matematika dan budaya saling berkaitan, matematika dapat lahir dari budaya, matematika dapat digali dalam budaya [3]. Hal yang sama dikemukakan bahwa kehadiran matematika yang bernuansa budaya akan memberikan kontribusi yang besar terhadap matematika sekolah [4].

Sebagai contoh pada bangunan salah satu kekayaan budaya Indonesia yaitu Candi Borobudur tampak bahwa konsep geometri yang diaplikasikan. Konsep geometri itu merupakan salah satu bagian dari matematika. Selain candi, aktivitas membatik termasuk khas kebudayaan di Indonesia, pada Proses membatik mengandung etnomatematika antara lain aktivitas membilang, mengukur, dan menghitung [5]. Contoh lain yaitu pada adat Lampung yaitu Siger. Siger merupakan perangkat adat penting dalam ritual tradisional masyarakat Lampung. Siger menjadi simbol kedaerahan yang melekat pada Provinsi Lampung Siger memiliki bentuk simetris bilateral, memanjang ke arah kiri dan kanan. Di bagian atas, terdapat lekukan dengan jumlah spesifik. Jumlah lekukan di bagian atas mencirikan asal wilayah siger tersebut berasal. variasi bentuk siger berkembang seiring perkembangan tradisi didalam masyarakat adat di Lampung. Hal ini terlihat dari perbedaan bentuk siger dalam masyarakat adat Saibatin dan Pepadun. Siger dalam adat Saibatin yang mendiami daerah pesisir memiliki tujuh lekukan yang bermakna tujuh adoq (gelar adat dalam masyarakat Saibatin) yaitu suttan/dalom/pangeran (kepaksian/marga), raja jukuan/depati, batin, radin, minak, kimas, dan mas/itton. Adapun siger dalam adat Pepadun memiliki sembilan lekukan yang melambangkan adanya sembilan marga (abung siwo megou).

Kemudian Djujor termasuk ritual adat pernikahan di Lampung. Muli atau gadis akan diambil oleh mekhanai atau pria bujang untuk dijadikan sebagai istri. Sang mekhanai dan keluarganya harus membayar bandi lunik atau mahar kepada wali sang muli. Muli juga memiliki permintaan yang disebut kiluan yang menjadi haknya dan harus dipenuhi mekhanai. [6] Ada dua cara yang bisa dilakukan untuk pelaksanaannya, yaitu secara sembunyi-sembunyi (Sebambangan) dan terang-terangan (Tekahang). Pada ritual djujor ini, ada pula keharusan untuk 
membawa 24 macam kue adat kepada keluarga si gadis. Mahar harus dibayarkan kepada kepala adat pihak si gadis secara kontan.

Dengan memanfaatkan kegiatan PERMATA-SAKTI ini sangat tepat untuk saling mengenalkan antar kebudayaan yang ada di Indonesia melalui interaksi lintas budaya. Untuk itu kegiatan pengabdian dilakanakan dengan tujuan untuk memfasilitasi kegiatan interaksi lintas budaya melalui bingkai pertukaran mahasiswa Nusantara dengan mengungkap adanya implementasi matematika pada kebudayaan lokal yang ada di Indonesia.

\section{METODE PELAKSANAAN KEGIATAN}

Metode pelaksanaan kegiatan PKM ini terdiri dari tiga tahapan yaitu tahap persiapan, tahap pelaksanaan dan tahap evaluasi. Kegiatan pada tahap persiapan yaitu mempelajari masalah tentang kebudayaan, mendata mahasiswa, dan melibatkan mahasiswa untuk bersama-sama menganalisis kebudayaan pada masingmasing daerahnya yang terintegrasi matematika. Kegiatan pada tahap pelaksanaan adalah membimbing mahasiswa memperkenalkan kebudayan daerahnya yang terintegrasi matematika, disajikan dalam bentuk video, dan dipresentasikan melalui webinar. Pada tahap evaluasi, mahasiswa merevisi video berdasarkan saran dosen dan peserta lain saat webinar.

Peserta pada kegitan PKM ini adalah mahasiswa PERMATA-SAKTI yang mengikuti matakuliah metode numeric di
Universitas Muhammadiyah Pringsewu (UMPRI) Lampung tahun ajaran 2020-2021 yang berjumlah 46 mahasiswa dengan rician 40 mahasiswa berasal dari UMPRI sekaligus tuan rumah, 3 mahasiswa berasal dari Universitas 17 Agustus 1945, 2 mahasiswa berasal dari Universitas Muhammadiyah Sorong, dan 1 mahasiswa berasal dari Universitas Ahmad Dahlan.

\section{HASIL DAN PEMBAHASAN}

Berdasarkan beberapa tahapan metode pelaksanaan kegiatan PKM, telah didapatkan hasil sebagai berikut:

\section{Tahap persiapan}

Kegiatan pada tahap persiapan ini dilaksanakan selama 2 hari pada pekan pertama di bulan November 2020. Berikut pemaparan kegiatan pada tahap persiapan.

a) Mempelajari permasalahan mitra.

Berdasarkan wawancara terhadap mahasiswa dari 4 perguruan tinggi mitra yang tergabung pada program PERMATASAKTI, telah ditemukannya masalah pada kebudayaan, yaitu sebagian besar mahasiswa tidak mengenal kebudayaan yang ada di daerah mereka sendiri, terlebih di daerah lain.

b) Pendataan mahasiswa,

Diperoleh data sampel sebanyak 9 mahasiswa dari 4 perguruan tinggi yang berbeda dan dari 6 daerah yang ada di Indonesia yang akan dibimbing untuk mempresentasikan kebudayaan dari daerah masing-masing sebagai bentuk kegiatan pengabdian kepada masyarakat ini. Namanama mahasiswa yang mengikuti kegiatan ini 
dapat di lihat pada table 1 berikut.

Tabel 1. Data mahasiswa

\begin{tabular}{lll}
\hline Inisial & \multicolumn{1}{c}{ Asal PT } & Asal Daerah \\
\hline IJS & Universitas 17 agustus & NTT \\
FN & Universitas 17 & Madura \\
CN & Universitas 17 agustus & Kal-Tengah \\
ANM & Universitas Ahmad DahYogyakarta \\
NIHS & Uni-Muda Sorong & Sorong \\
CGY & Uni-Muda Sorong & Sorong \\
IN & UMPRI Lampung & Lampung \\
WRA & UMPRI Lampung & Lampung \\
PT & UMPRI Lampung & Lampung \\
\hline
\end{tabular}

c) Analisis kebudayaan

Tim pengabdian melibatkan mahasiswa untuk bersama-sama menganalisis kebudayaan pada masing-masing daerahnya yang terintegrasi matematika, dan diperoleh data sebagai berikut:

1) Budaya Lampung: aplikasi matematika pada bentuk lengkungan siger, ritual Djujor, pola desain kain tapis, bentuk rumah adat, dan sebagainya.

2) Budaya Yogyakarta: aplikasi matematika pada filosofi jumlah tangga di makam raja-raja Imogiri, pada alat music gamelan, dan pada candi-candi yang ada di Yogyakarta.

3) Budaya Sorong: aplikasi konsep matematika yaitu jumlah ketukan parang pada ritual pernikahan suku Moi dan desain gambar pada kain timor Sorong

4) Budaya Surabaya: aplikasi matematika pada filosofi jumlah tiang di masjid Sunan Ampel.

5) Budaya Madura: Aplikasi konsep matematika pada taneyan lanjeng seperti garis lurus, garis lengkung, garis sejajar, simetri, titik, sudut, dan sebagainya.

6) Budaya NTT: aplikasi konsep matematika pada rumah adat bajawa, dan pengukuran pada tradisi belis.

7) Budaya Kalimantan Tengan: aplikasi matematika pada tradisi sumpitan yaitu pada bentuk sumpit yang menggunakan konsep geometri seperti tabung, kerucut, dan sebagainya.

\section{Tahap Pelaksanaan}

Kegiatan pada tahap pelaksanaan adalah membimbing mahasiswa memperkenalkan kebudayan daerahnya yang terintegrasi matematika dan disajikan dalam bentuk video, dan memfasilitasi diskusi lintas budaya antar mahasiswa dengan mempresentasikan video yang telah dibuat melalui webinar.

a) Membimbing mahasiswa membuat video pengenalan budayanya masing-masing dengan diintegrasikan dengan konsepkonsep matematika. Pembimbingan ini dilaksanakan pada tanggal 4-7 November 2020. Berikut adalah dokumentasi pelaksanaan pembimbingan kepada mahasiswa melalui online.
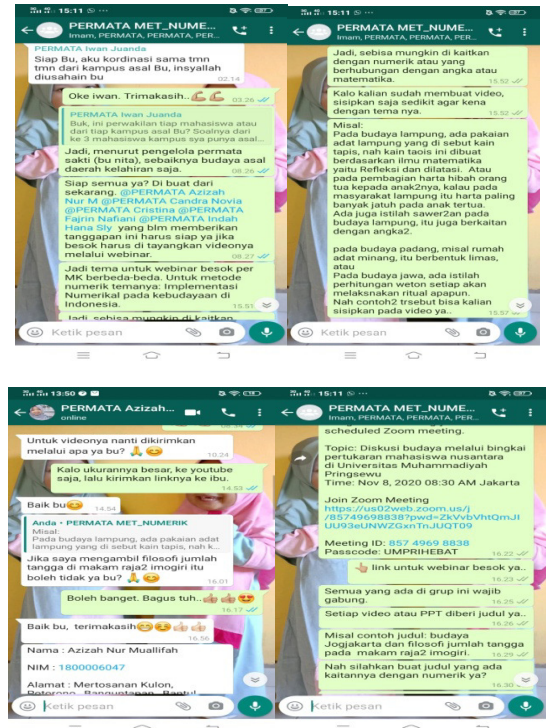

Gambar 1. Dokumentasi proses bimbingan 
b) Memfasilitasi diskusi lintas budaya antar mahasiswa yang tegabung pada program PERMATA-SAKTI melalui webinar. Kegiatan diskusi lintas budaya ini dilaksanakan pada tanggal 9 November 2020 pukul 09.00-12.00 WIB melalui webinar nasional dengan menggunakan aplikasi zoom meeting. Tim pengabdi bertugas sebagai moderator, fasilitator sekaligus narasumber. Sedangkan para peserta mahasiswa yang telah terpilih, masing-masing mempresentasikan video atau PPT yang telah dibuat tentang pengenalan budaya dari daerah asalnya, serta peserta yang lain ikut serta berinteraksi, berdiskusi atau tanya jawab.

Berikut adalah dokumentasi kegiatan diskusi lintas budaya antar mahasiswa Nusantara dalam webinar nasional.

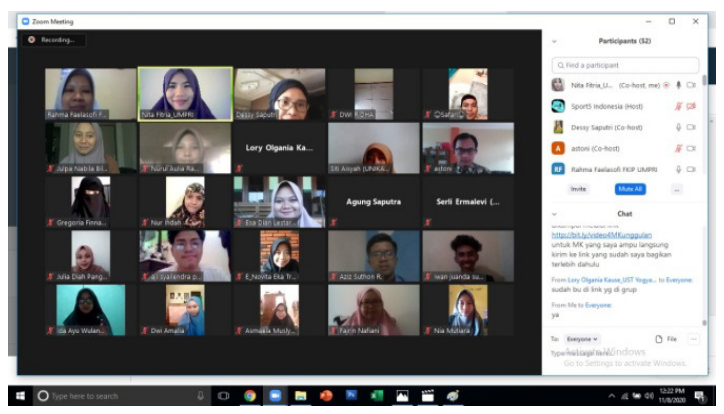

Gambar 2. Webinar nasional

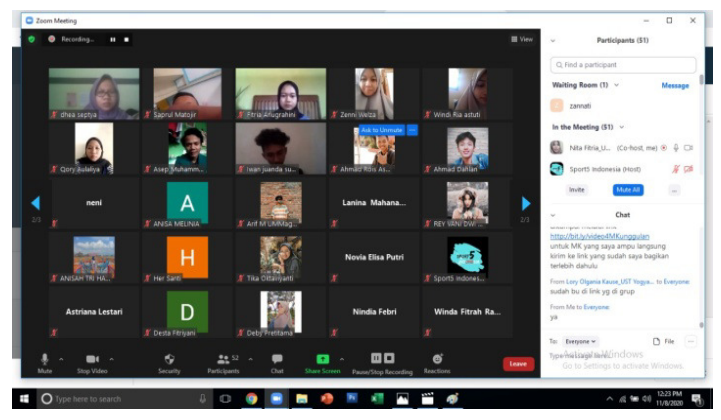

Gambar 3. Webinar nasional

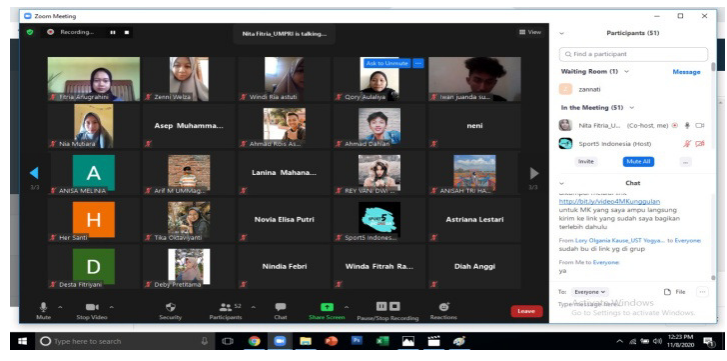

Gambar 4. Webinar nasional

\section{Tahap evaluasi}

Pada tahap evaluasi, tim pengabdi menganalisis video yang telah dibuat oleh peserta kegiatan PKM, lalu mahasiswa diminta untuk merevisi video berdasarkan saran tim pengabdi dan peserta lain saat webinar.

Adapun analisis pencapaian kinerja kegiatan antara lain:

1) Kegiatan didukung penuh oleh Universitas Muhammadiyah Pringsewu Lampung

2) Peserta antusias terhadap materi yang disampaikan.

3) Peserta antusias dan termotivasi untuk mengenal berbagai kebudayaan yang ada di Indonesia lebih lanjut.

4) Target terfasilitasinya interaksi lintas budaya antara mahasiswa yang berasal dari berbagai daerah di Indonesia telah terpenuhi.

5) Target meningkatnya pengetahuan mahasiswa tentang kebudayaan di Indonesia telah terpenuhi.

6) Meningkatnya kemampuan berpikir kritis melalui analisis konsep matematika yang ada pada kebudayaan di Indonesia.

7) Menghasilkan video kegiatan yang terekam dari hasil recording aplikasi zoom pada saat kegiatan webinar dan 
secara lengkap dapat dengan mudah di inspirasi atau ide dalam melaksanakan unduh dan di tonton melalui youtube, penelitian tentang nilai-nilai apa saja yang sehingga memudahkan bagi mahasiswa terkandung pada budaya di Indonesia, tinggal dan masyarakat yang belum mengikuti kegiatan tersebut untuk mengenal lebih dalam berbagai kebudayaan di Indonesia.

8) Menghasilkan video pengenalan budaya dari berbagai daerah di Indonesia.

9) Menghasilkan artikel yang diseminarkan pada seminar nasional hasil pengabdian kepada masyarakat yang diselenggarakan oleh Jurusan THP Fakultas Teknologi Pertanian Universitas Andalas Padang Sumatera Barat tahun 2020.

\section{KESIMPULAN}

Kesimpulan dari hasil kegiatan ini adalah melalui kegiatan webinar ini, a) interaksi lintas budaya antara mahasiswa yang berasal dari berbagai daerah di Indonesia telah terfasilitasi, b) meningkatnya pengetahuan mahasiswa tentang kebudayaan di Indonesia, c) menghasilkan video pengenalan budaya dari berbagai daerah di Indonesia, dan d) meningkatnya kemampuan mahasiswa untuk berpikir kritis melalui analisis konsep matematika yang ada pada kebudayaan di Indonesia.

\section{SARAN}

Kegiatan pengabdian kepada masyarakat seperti ini sebaiknya dapat di jadikan rekomendasi untuk PKM berikutnya. Bisa dengan menganalisis atau mengintegrasikan ilmu pengetahuan lain selain matematika yang mungkin tanpa disadari telah diaplikasikan pada budaya yang ada di Indonesia, bisa juga menjadi 
bagian dari proses kegiatan pengabdian

kepada masyarakat ini melalui diskusi yang

berkelanjutan baik pada saat kegiatan

berlangsung maupun di luar kegiatan.

Semoga amal baik mereka diterima disisi

Allah SWT sebagian dari amal shaleh dan

ilmu yang bermanfaat.

\section{REFERENSI}

[1] Euis, F. 2018. Peran Etnomatematika Terkait Konsep Matematika dalam Mendukung Literasi. Prisma 1:114-119 https://journal.unnes.ac.id/sju/index.php/ prisma/

[2] Albert, E. P. 2020. Konsep Pembelajaran Daring berbasis pendekatan Ilmiah. Jawa Tengah: CV Sarnu Untung

[3] Hardiarti, S. 2017. Etnomatematika:
Aplikasi Bangun Datar Segiempat Pada Candi Muaro Jambi. Aksioma. 8(2) : 99110

[4] Sudirman, dkk, 2018. Pengggunaan Etnomatematiika Pada Batik Paoman dalam Pembelajaran Geometri Bidang di Sekolah Dasar. Indomath: Indonesian Mathematics Education 1 (1): 28

[5] Umy, Z. 2020. Pembelajaran Berbasis Etnomatematika Dengan Memodelkan Motif Batik Gajah Mada. Jurnal Dinamika Penelitian: Media Komunikasi Sosial Keagamaan 20(1): 1-17

[6] Liputan 6. 2019. Adat Yang Unik dan Terkenal di Lampung. Liputan6.com. https://www.liputan6.com/lifestyle/read/ 4029387/6-adat-yang-unik-dan-terkenaldi-lampung 